\title{
1. I3P as university business incubator - a dual mission in technology transfer and start-up ecosystem development Marco Cantamessa
}

\subsection{UNIVERSITY INCUBATORS IN REGIONAL INNOVATION SYSTEMS}

In the literature dealing with innovation systems, policies and instruments designed to stimulate entrepreneurship and foster new venture creation feature strongly (Hekkert et al., 2007). In reality, a key avenue for the innovation process seems to pass through the creation and growth of new, innovative firms. Start-ups can influence the innovation performance of a territory through their growth, as well as through the positive impact they can have on incumbent firms through trade in new goods and services, knowledge spillovers and competition (Erkko and Yli-Renko, 1998).

The nurturing of start-ups is therefore generally considered a key element in regional innovation policy. Scholars, consultants and policymakers have long viewed the creation of an environment conducive to new and successful start-ups as the 'holy grail' of a regional innovation system, and it is very common for those engaged in this field to share the dream of creating 'their own Silicon Valley'.

Given this aim, in recent decades incubators have been seen as useful tools for stimulating the process by which new technology-based companies are created and matured. Over the years, start-up incubation has been subject to a variety of models, including public vs. private ownership, non-profit vs. for-profit orientation, narrow vs. generalist sectorial specialization and multiannual incubation programs vs. very short 'acceleration' initiatives (Peters et al., 2004).

Among the actors developing incubation programs, universities have always played a key role. This has occurred because of the increasing attention paid by academic institutions towards their 'third mission' 
(i.e. economic development, alongside their traditional orientation towards research and education (Zomer and Benneworth, 2011)) and towards the associated emergence of the so-called 'entrepreneurial university' (OECD-EC, 2012). In this context, universities have approached start-up incubation with the dual aim of bringing research results and technical competencies to the market, and of providing practical entrepreneurial opportunities for their academic staff and students. In an 'entrepreneurial university', entrepreneurship can therefore be viewed as a practical avenue for technology transfer, as a subject to be researched and taught, and as a general mindset that permeates the institution at a more general level (Cantamessa, 2015).

University incubation programs generally do not exist in isolation. They are part of the broader strategy with which an academic institution relates to its social and economic environment. Therefore, they are an integral part of the so-called 'Triple Helix' model of innovation (Etzkowitz and Leydesdorff, 2000) that links the actions of academia, industry and policymakers in what hopefully becomes a complementary and synergistic action.

As such, managing a university incubation program is complex. Aside from the inner complexity of carrying out its core business of translating business ideas into successful companies, it must tackle the outward complexity of effectively linking with the academic milieu and with the regional socioeconomic environment, exploiting this potential and co-evolving with it.

The aim of this chapter is to shed some light on the multifaceted nature of university incubation, starting with a single data point represented by the I3P incubator of Politecnico di Torino in Italy. A single case study is obviously not sufficient to provide a robust empirical grounding that will lead to either the exploration of hypotheses to be tested or - even more so - to the confirmation of conclusions. Therefore, this chapter limits its ambition to providing anecdotal evidence that may stimulate further debate and research on the topic of academic incubation programs. The following section will provide a brief description of I3P's history, followed by an analysis of the main aspects that characterize a university incubator from an economic perspective, and attempt to draw some managerial implications.

\subsection{THE EXPERIENCE OF I3P}

\subsubsection{History and Profile}

I3P is the technology incubator of Politecnico di Torino, Italy's second largest technical university, ranked sixteenth in Europe by the QS2014 
ranking for technical universities. It has 33,000 undergraduate and graduate students (of which 700 are at doctoral level), 800 lecturers and an annual budget of 260 million euros.

I3P is located in the city of Turin, in the northwestern part of the country. Turin is a medium-sized city with 870,000 inhabitants (1.7 million including its metropolitan area) and a long industrial tradition. The city's industrial focus has progressively moved from textiles in the nineteenth century to automotive and aerospace in the twentieth century. At the end of the 1990s, the Municipality initiated its first Strategic Plan, with the objective of leading the transformation of the city and its surroundings beyond the traditional dominance of the automotive industry. Turin at that time was considered 'Italy's Detroit', but with the difference that a single carmaker (Fiat) was the dominant player, with links to the city that were seen to be dwindling, along with a perceived lack of competitiveness in a globalizing world. One of the chapters in the Strategic Plan concerned the nurturing of new high-tech businesses, and the establishment of an incubator was therefore included in the plan. The I3P incubator was set up in 1999 as an independent non-profit-making company owned by the Politecnico di Torino and the local public authorities (the Municipality, the Provincial and Regional Governments, the Chamber of Commerce), each with equal voting rights.

This shared ownership and the strategic orientation of its shareholders led I3P to envisage a broader mission than simply supporting university spin-offs, and to define itself as an actor aiming to create qualified jobs through the growth of high-tech start-ups. Therefore, from the outset I3P started scouting for entrepreneurial ideas not only within the university, but also across the region. Currently, each stream accounts for around half of all applications coming to I3P. The former includes ideas derived from research projects (usually with a strong scientific grounding but an unclear business applicability) as well as simpler business ideas coming from students. The latter mostly consists of applications from entrepreneurs living in the area, many of whom are alumni of the university, or attracted to Turin and to the Politecnico campus because of the technical and industrial competencies they find there. Additional applications come from companies wishing to create corporate spin-offs, usually in an attempt to extract value from non-core projects that have been developed up to a preliminary stage and to provide entrepreneurial incentives to staff in charge of these projects.

This broader mission and orientation had a second implication. It was decided not to specialize the incubator in a specific technology or industry, but to cover all the fields in which Politecnico di Torino could provide competencies (effectively excluding only biotechnology and pharmaceuticals). 
The first corollary of this generalist orientation was not to set up shared laboratory facilities. Start-ups are invited to set up their own labs as long as the investment is reasonable, and to partner with academic departments when capital-intensive equipment is required. This decision allowed the incubator to reduce its capital and operating expenditures and - as a consequence - to stimulate exchanges between start-ups, and between start-ups and academic departments. I3P recognized that a generalist strategy ran the risk of de-focalization. To counter this, it aimed at developing a large-scale incubation program, which would allow the specialization of its team of coaches ${ }^{1}$ in industry-specific 'practices', following the model of management consultancy companies. Currently, I3P is organized into four practices: IT/Internet, CleanTech, MedTech and Automation. In other words, it was thought that a large incubator made up of multiple practices would simultaneously offer the advantages of both specialized and generalist orientations. Each practice involves senior coaches who have significant experience in supporting start-ups, junior consultants who provide most of the contact hours with the start-ups, and junior trainees who support the most labor-intensive activities, such as collecting market information and setting up economic and financial models and cap tables. In order to create a flexible organization and to imbue it with greater entrepreneurialism, I3P coaches are mostly freelancers employed by the incubator on medium-term contracts and for a substantial portion of their working time, although they do not work exclusively for the incubator. This gives them the freedom to work with external clients and contribute to the diffusion of a 'start-up culture' across the territory.

I3P's close relationship with its public shareholders allows it to quickly launch initiatives and respond to trends while leveraging its cumulated experience. For instance, when in 2012 the Municipality launched an initiative to support start-ups in the field of social innovation, it did not have to establish a new entity. Rather, it worked with I3P (which provided entrepreneurial know-how and the enabling technology, along with its sister incubator at the University of Turin) and with other partners who contributed specific experience in the field of social innovation.

As a publicly owned entity, I3P constantly runs the risk of passively relying on public funding, thus impairing the sustainability of its business model and - most of all - losing its entrepreneurial streak, which would contradict its mission and damage its credibility among start-up founders. Therefore, the business model of I3P has been subject to a number of experiments, until a satisfactory solution was found in 2008. This solution stemmed from the recognition that, given the time required for start-ups to grow and the absence of private donors, there was a market failure that justified public contribution. However, it was also decided that this 
contribution, drawn from the European Social Fund (ESF) budget of the Piedmont Region, should not cover all the incubator's expenses and should also include a correct set of incentives similar to those found in a wellfunctioning market. To address the former criterion, a 35\% revenue target coming from tenant companies was identified as a reasonable objective. To address the latter criterion, the funding scheme was linked to operational results and not only to the reporting of expenses - as required by ESF regulations. The mechanism works roughly like this: each time a new start-up is incorporated, I3P is authorized to claim reimbursement of expenses up to the predefined 'standard cost' of launching a new firm. Being paid according to the number of start-ups incorporated creates a clear incentive since - if the incubator should stop launching new companies - this would end both public funding and revenues derived from service fees paid by tenants. Given that the number of start-ups created is the main revenue driver of the incubator, this has spontaneously led to an MBO (Management By Objectives) mechanism, in which each of the incubator's practices is evaluated according to the start-up creation process (i.e. number of applications received, number of start-up projects worked upon, and actual number of start-ups incorporated).

An alternative business model, based on taking equity from start-ups, was considered but not adopted, mainly because of the time required to grow a start-up on the Italian market. Moreover, this would have biased the activity of the incubator towards 'quick wins' and away from projects with a stronger technology base, which require a longer time-to-market. Finally, because public institutions own I3P, legislative complexity would have made the management of these equity stakes fraught with compliance risk and administrative overheads.

\subsubsection{The Incubation Process}

The incubation process followed by I3P is relatively standard and based on four main activities.

Scouting concerns finding new entrepreneurs and business ideas. One key avenue for scouting is via person-to-person and word-of-mouth contacts within the Politecnico di Torino and its labs, as well as in the local territory. Alongside this, I3P organizes a significant number of events, such as Start-up Weekends, thematic hackatons (many sponsored by large companies) and an annual Business Plan Competition. This competition is part of a nationwide program run by PNICube, the association of Italian university incubators. In 2011, I3P also launched an acceleration program called Treatabit, aimed at fast-tracking internet start-ups. Altogether, these activities lead to more than 300 applications per year to the incubation 
program. All applications lead to a direct contact between incubator coaches and entrepreneurs and to the establishment of a preliminary consultancy path. Following these early steps, it becomes progressively clear whether a project should be supported or abandoned.

Consultancy covers all the phases starting from initial screening and throughout the mentoring and coaching activities that allow business ideas to become well-structured projects (more than 100 per year) and - later - start-ups (about 20 per year). I3P focuses its consultancy on strategy and - depending on the type of start-up - follows either a traditional approach based on business modeling and business planning, or the recent Lean Start-up approach (Ries, 2011). Besides strategic consultancy, projects and start-ups benefit from the technical expertise of Politecnico di Torino and other technology partners. Moreover, entrepreneurs receive specialized consultancy in administrative, legal and intellectual property matters from professional services firms that I3P has selected as partners and that provide high-quality services at modest rates. From the perspective of these partner firms, this is a way to gain new customers and to create competencies and a reputation on the start-up market. From the perspective of I3P, these partnerships allow it to provide cost-effective and high-quality services to its start-ups, while at the same time stimulating existing local actors into contributing to the creation of a richer start-up ecosystem.

Teambuilding and fundraising concerns projects that are mature enough to attract talent and capital, and continues throughout the growth of the start-up. Often, the initial entrepreneurial team is not strong enough, or lacks either technical or managerial competencies. The incubator therefore uses its network to attract key personnel either as co-founders or as employees for the nascent start-up. Once this is accomplished, the start-up can be presented to equity investors for an initial funding round. Typical investors include business angels and venture capital funds, together with local companies willing to operate an informal style of corporate venturing. I3P specializes in seed financing, with rounds ranging from 50,000 euros (typical for internet start-ups) to 500,000 euros (typical for a CleanTech or MedTech initiative) and an average annual fundraising amounting to 3 million euros. I3P also supports fundraising for subsequent financing rounds, although the results remain fairly meager, given the weakness of the Italian venture capital industry, which includes few active early-stage funds. Hopefully, recent legislation that grants tax breaks to investors in start-ups and in venture capital funds will stimulate the industry and lead to a higher number of players.

I3P also supports debt fundraising, which is applicable whenever a start-up is close to achieving revenue. Banks are generally reluctant to lend 
money to start-ups, but I3P's reputation allows it to obtain preferential treatment for the start-ups it vouches for, based on collateral-free mediumterm loans (six years, including one initial year in which the start-up must pay interest but no principal) ranging from 100,000 to 500,000 euros.

Business development deals with facilitating and supporting connections between start-ups and the market, and is probably the main activity carried out by I3P during the incubation program, which lasts three years after incorporation (plus two optional years of 'post-incubation acceleration'). Most start-ups at I3P operate in B2B markets. This makes it imperative to overcome the barriers that are often in place when a startup attempts to interact with large corporations. Business development activity at I3P is relatively recent and started around 2010, when a few large companies showed interest in working with start-ups, along the lines of Open Innovation (Chesbrough, 2006). At present, I3P runs this activity mostly by organizing company-specific visits during which the senior management of a large company meets a selection of start-ups it might be interested in (usually eight to ten), provides feedback and chooses a subset (usually one to three) with which it may start a pilot project. These pilot projects can then lead to a fuller commercial relationship and/or to a corporate investment. Experience shows that it is imperative to have senior decision-makers taking part in these events. Middle managers often enthuse about the start-ups they see, but do not have the organizational clout to make the relationship progress at a later stage when the company slows down the process because of organizational inertia or because of internal opposition to working with start-ups.

In addition to corporate visits, I3P also promotes the participation of start-ups at international trade fairs, usually by renting a booth and sharing the costs.

\subsubsection{Current Results and Future Trends}

One key result of any incubation program is its capacity to generate new companies. Since its inception in 1999 and up to mid-2015, I3P has launched 175 start-ups, of which 40 are still in the incubation program. Of the remaining 135, 31 have gone out of business, 11 have been acquired, and the remaining 93 are surviving (one of which has gone through an Initial Public Offering (IPO)). Over the years, the low failure rate (under $20 \%$ ) has received mixed reactions, with some stakeholders expressing satisfaction and others being somewhat perplexed. The former consider a high success rate as a positive indicator per se and as an indicator of a sound screening process. The latter consider the low failure rate as an indicator of a 'low risk-low reward' profile of I3P's start-ups. In principle, 
both perspectives are reasonable, but one must consider the business model mix of the start-ups being launched. During its early years, I3P worked mainly with start-ups characterized by a service-oriented business model, and with relatively few high-growth, product-based and high-risk startups, especially because at that time there was not enough equity funding available. Unsurprisingly, service-oriented businesses are less risky and account for the overall high success rate reported above. Given the progressive growth of equity funding available, the mix of start-ups has shifted towards product-based and riskier initiatives, which instead make up most of the failures.

Another important indicator of an incubation program is job creation. As shown in Figure 1.1, at the end of 2014, I3P start-ups have generated 1,400 direct jobs. By using well-known multipliers that take into account the value chains in which start-ups operate and broader economic spillovers (Moretti, 2012), it is possible to estimate the overall employment impact to range between 6,000 and 7,000 units.

The distribution of these jobs follows a Pareto distribution, with a small minority of larger companies making up the bulk of this impact. More precisely, one start-up has grown to more than 400 employees, four to five have grown to around 50, with the rest being small companies with an average

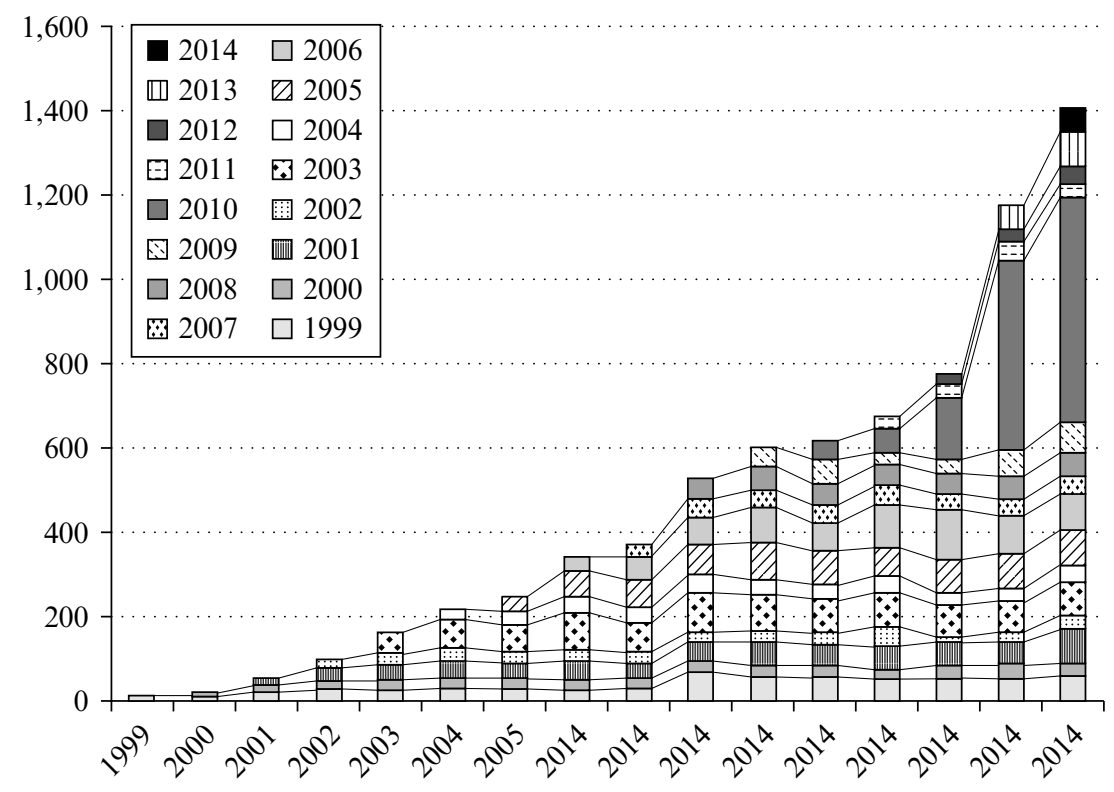

Figure 1.1 Job creation by I3P start-ups, by year of incorporation 


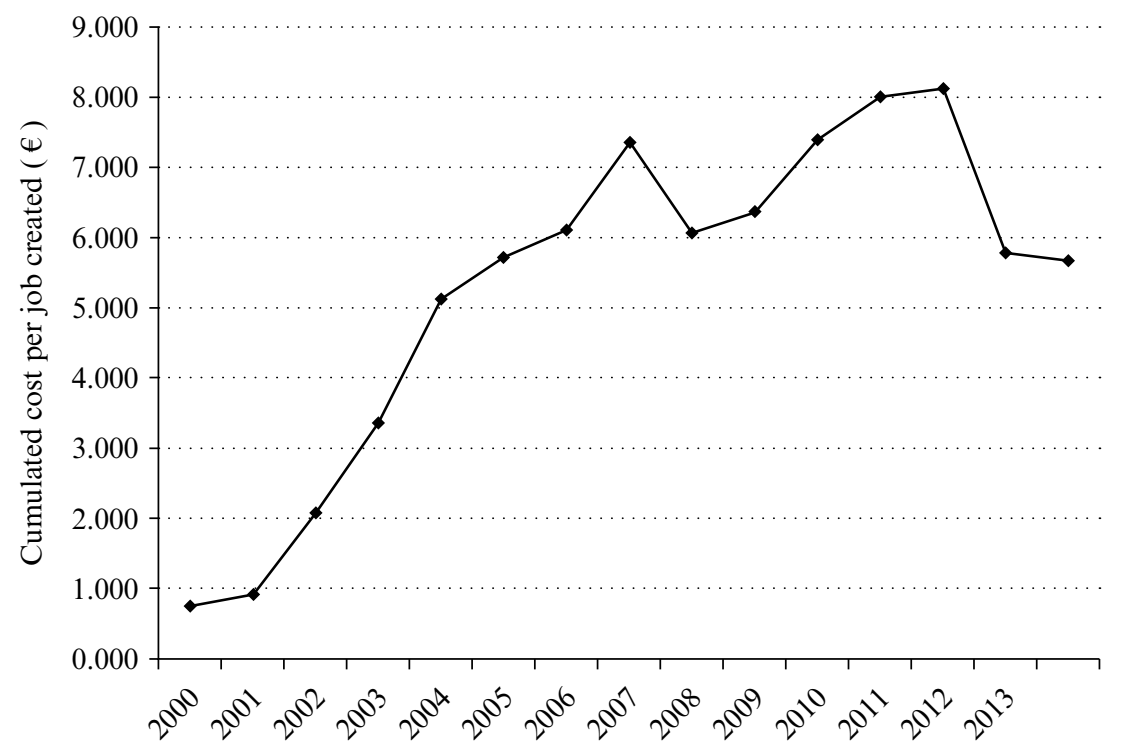

Figure 1.2 Public expenditure per job created at I3P

of five to six employees, some of which are still growing and others not. If the objective of an incubator is to generate large, world-class companies, even a sizable entity such as I3P has apparently failed to deliver. However, if the aim of an incubator is the progressive generation of a resilient stream of high value-adding jobs, while trying to generate large 'champions', then the results shown can be considered a success. Moreover, if one divides the cumulated public funding used by I3P by the number of direct jobs created, one comes up with a nearly constant value of 6,000 euros (see Figure 1.2). A one-off investment of 6,000 euros obviously constitutes a sound return for the taxpayer, given the amount of taxes and social contributions paid by each of these new employees every year.

The world of start-ups is not static. Any incubation initiative must continuously evolve in order to cater to the needs of its customers and achieve a better fit with the overall start-up ecosystem to which it belongs. In 2015, I3P was working in three main directions to shape its activities in the medium term.

The first is attracting start-ups from outside the region, leveraging the competencies available at Politecnico di Torino and, more broadly, in the surrounding territory. Turin is an interesting development hub especially for technology start-ups with some degree of manufacturing content. The city is strategically placed in Europe, provides a high number of qualified 
science, technology, engineering and mathematics (STEM) graduates at comparatively low salaries and offers them a good quality of life. Moreover, the city has an impressive number of manufacturing suppliers with experience of working to the stringent standards of the automotive and aerospace industries. Start-ups can connect with these manufacturers and go from a prototype to production very quickly and with minimum investment.

The second is to create tighter links with large corporations. A number of companies already working with start-ups from I3P have recognized that in order to be effective, the interaction process with start-ups must be more structured. Moreover, they have noticed that in order to successfully adopt the technologies and products being developed by these start-ups, their own products and processes must co-evolve. This calls for the development of corporate incubation programs in which entrepreneurs work closely together with incubator coaches and corporate champions and mentors. Given their lack of experience and the high cost involved in running a proprietary corporate incubation program, a number of large companies have asked I3P to host such programs along the lines of a 'white label' or 'jointly-run' model.

Finally, some limitations have been recognized in I3P's ability to foster the growth of its start-ups, which is mainly due to its public nature. In fact, by not taking equity stakes, I3P coaches cannot have a direct and active role in the governance of start-ups. In some cases, investors and entrepreneurs have asked I3P coaches to take on a more active role, assuming directorships or interim managerial positions. In order to facilitate and regulate this kind of activity, which clearly goes beyond the 'public' mission of I3P, a parallel 'acceleration program' privately run by consultants and coaches will be set up.

\subsection{SOME CONSIDERATIONS FOR THE BUSINESS MODEL OF A UNIVERSITY INCUBATOR}

\subsubsection{The Economic Foundations of a University Incubator}

It is not easy to define what a university start-up incubator is from an economic perspective. However, based on the previously discussed case study, it is possible to highlight four main economic roles and their characterizing features. As mentioned earlier, this discussion is based on a single case study and therefore represents a set of hypotheses and can by no means be considered as a validated result.

A university incubator is first a consultancy company, in which an 
experienced group of coaches and mentors provide inexperienced teams of entrepreneurs (or entrepreneurs lacking the full range of competencies) with the advice they need to set up and grow a start-up. The role of these consultants is to bring specialist knowledge and prior experience to quicken the process. Moreover, as a consultancy, the incubator can help entrepreneurs avoid costly mistakes resulting from either inexperience or typical cognitive biases (Simon et al., 2000), and thus reduce the failure rate of start-ups passing through the program. Because this activity is laborintensive, it would not appear to generate significant economies of scale. In reality, economies of scale can emerge if the number of client companies is high enough to enable the structuring of a hierarchy of coaches, from junior trainees to senior consultants, thus optimizing the mix of expertise and hourly costs attached to each activity. Moreover, consulting activities clearly benefit from learning economies. These may arise both in domainindependent aspects (e.g. structuring a financial plan for a start-up or preparing a sales pitch) as well as industry-specific aspects (e.g. knowing the latest trends in photovoltaic plants). Therefore, a successful incubation program may require a minimum track record both in its overall activities and its activity in each industry that it chooses to operate in. Returning to the case of I3P, this dual level of experience explains the simultaneously multi-industry and large-scale approach.

A further element for consideration in the incubator's role as a consultancy is associated with the degree to which the incubator's coaches and mentors may intrude in start-ups' decision-making processes. This can range from friendly, informal advice that start-ups are under no obligation to heed, all the way to full and formal involvement in a start-up's governance. The degree of involvement has to do with the experience of the pool of coaches and mentors, with the public or private nature of the incubator, to the set of incentives it is subject to, and to the degree of potential liability the incubator is willing to bear.

A university incubator is also a two-sided market (Rochet and Tirole, 2006). One side of the market is made up of entrepreneurs who want to establish and grow their start-ups, while the other is made up of economic actors that want to interact with start-ups in a number of different capacities and roles. Individuals may wish to be hired; existing companies and professional services firms may look at the incubator's start-ups as potential suppliers or customers; investors will use the incubator to strengthen their deal flow.

As a two-sided market, size and variety matter significantly, thus leading to significant economies of scale and scope. Entrepreneurs will be attracted to an incubator if they know that the program will expose them to many, diverse and qualified economic actors. For their part, economic actors will 
be attracted to an incubator if they know that it hosts a large number of high-quality start-ups. Some of these economic actors may look for size and specialization, while others may be attracted by variety as well. For instance, a CleanTech venture capital fund will not be interested in a startup developing innovative HR employee benefits. However, a large corporation operating in the CleanTech industry may find that same start-up very interesting for its own HR services.

In the context of two-sided markets, an incubator has two main distinguishing features. First, the collection of economic actors who wish to interact with start-ups is not homogeneous, and this requires the setting-up of distinct and specific processes, which of course adds to the complexity of its operations. Secondly, the incubator is not usually a simple and neutral venue where entrepreneurs and economic actors interact freely and autonomously. Interactions between start-ups and other economic actors are inherently laden with uncertainty and risk, not to mention significant information asymmetries that may be present on either side, thus leading to moral hazard. In order to operate as an effective economic exchange, the incubator must therefore build a significant reputational capital (Hoppe and Ozdenoren, 2005) by running a careful screening process of the actors it involves and by supporting their interactions so as to minimize the risk of disruption and litigation. For the parties involved, interaction occurring within the boundaries of and overseen by the incubator provides a significant guarantee. These parties know that the incubator has a strong incentive to avoid problems that could damage its reputation and the value of its matchmaking activity. This reputational aspect is probably more relevant in start-up ecosystems that are not fully developed, and where the 'rules of the game' and the ethos of what it means to run - or cooperate with - a start-up are not yet widely known. Conversely, an incubator operating in an ecosystem with many experienced entrepreneurs and economic actors can probably limit itself to connecting them, and then leaving ample freedom for the parties involved to decide whether and how to proceed. In any case, the ability to work on individual connections and building reputational capital is probably the reason why incubators continue to exist and have not been supplanted by internet exchanges such as AngelList.

Bringing the two previous roles together, the incubator may also be viewed as a mini business cluster exhibiting economies of agglomeration (Porter, 1996). This perspective is interesting, because of the potential value of inter-firm relationships between start-ups. These relationships may occur at a formal level, when complementary start-ups cooperate with one another to develop complex products and services, or when competing start-ups cooperate or engage in small-scale merger and 
acquisition (M\&A) activities to achieve economies of scale and accelerate their evolution. Inter-firm relationships may also be informal and based on knowledge, experience and network sharing between individuals in an entrepreneurial community (Feld, 2011) including both current start-ups and alumni. It is uncertain whether this latter type of interaction should be considered as a complement or as a substitute for the formal consultancy and matchmaking activities carried out by incubator coaches and mentors. Should it be a substitute, it may lead incubators to progressively shrink their activity as the entrepreneurial community they have nurtured grows.

If one focuses on university incubators, a further role as a bridging institution for technology transfer emerges (Kremic, 2003). A significant part of a university incubator's activity is in fact associated with creating opportunities to exploit research results by supporting the launch of start-ups that may license such results and bring them to market. In this case, they follow a technology-push process (in other terms 'given the solution, what is an addressable problem and market?'). Moreover, university incubators often work on demand-pull innovation processes by supporting start-ups that answer a clear market need to tap into relevant technical competencies at the university. When dealing with the former type of process, the incubator will have to manage a potential conflict of interest between its primary duty towards entrepreneurs, which calls for maximizing the value of the start-up, and its institutional affiliation to the university, which instead might call for maximizing the returns accruing to the same institution. In order to avoid getting stuck in embarrassing positions and undermining its reputation, the incubator must ensure that regulations governing academic entrepreneurs and their relationship to the parent institution are clearly spelled out in advance.

In any case, acting as a successful bridging institution is likely to require an affiliation with a strong university, able to produce a variety of high-quality and market-relevant research and competencies. On the other hand, the bridging institution must have sound connections with the associated industries. Moreover, given the important differences between the technology-push and demand-pull processes as outlined above, the incubator must be able and flexible enough to manage both.

Table 1.1 attempts to summarize the previous discussion, pointing out the four economic roles, their possible economic drivers, the resulting key success factors and the related implications for incubator managers.

Based on this representation of the economic foundations of a university incubator, and taking into account the disclaimer that it represents a set of hypotheses, it is possible to draw some tentative conclusions 
Table 1.1 A summary of the possible economic determinants of academic incubation

\begin{tabular}{|c|c|c|c|}
\hline $\begin{array}{l}\text { Economic } \\
\text { role }\end{array}$ & Economic drivers & $\begin{array}{l}\text { Main actors and } \\
\text { key success factors }\end{array}$ & Strategic implications \\
\hline $\begin{array}{l}\text { Consultancy } \\
\text { company }\end{array}$ & $\begin{array}{l}\text { Learning } \\
\text { economies } \\
\text { (generic with } \\
\text { respect to } \\
\text { start-ups) } \\
\text { Learning } \\
\text { economies } \\
\text { (industry- } \\
\text { specific) } \\
\text { Scale economies } \\
\text { (allowing a } \\
\text { hierarchy of } \\
\text { consultants) }\end{array}$ & $\begin{array}{l}\text { Coaches and } \\
\text { mentors (and } \\
\text { their ability as } \\
\text { consultants) }\end{array}$ & $\begin{array}{l}\text { Deciding whether to } \\
\text { pursue a generalist } \\
\text { or specialist strategy } \\
\text { Deciding the degree } \\
\text { to which coaches } \\
\text { and mentors can } \\
\text { play an active } \\
\text { part in start-ups' } \\
\text { decision-making } \\
\text { processes }\end{array}$ \\
\hline $\begin{array}{l}\text { Two-sided } \\
\text { market }\end{array}$ & $\begin{array}{l}\text { Economies of } \\
\text { scale and scope } \\
\text { on the multiple } \\
\text { markets involved } \\
\text { Reputational } \\
\text { capital and } \\
\text { ability to } \\
\text { support } \\
\text { transactions } \\
\text { with high } \\
\text { uncertainty and } \\
\text { information } \\
\text { asymmetries }\end{array}$ & $\begin{array}{l}\text { Size, variety and } \\
\text { quality of the } \\
\text { pool of start-ups } \\
\text { Size, variety and } \\
\text { quality of the } \\
\text { external network } \\
\text { Coaches and } \\
\text { mentors (and } \\
\text { their ability as } \\
\text { matchmakers) }\end{array}$ & $\begin{array}{l}\text { Deciding the effort to } \\
\text { be spent on building } \\
\text { the different } \\
\text { markets and the } \\
\text { directions to take }\end{array}$ \\
\hline $\begin{array}{l}\text { Industry } \\
\text { cluster }\end{array}$ & $\begin{array}{l}\text { Economies of } \\
\text { agglomeration } \\
\text { (scale and } \\
\text { scope) }\end{array}$ & $\begin{array}{l}\text { Size, variety and } \\
\text { quality of the } \\
\text { pool of former } \\
\text { and current } \\
\text { start-ups } \\
\text { Richness, } \\
\text { experience and } \\
\text { connectedness } \\
\text { of the } \\
\text { entrepreneurial } \\
\text { community }\end{array}$ & $\begin{array}{l}\text { Deciding the effort to } \\
\text { be spent on } \\
\text { creating inter-firm } \\
\text { connections among } \\
\text { start-ups and } \\
\text { alumni } \\
\text { Monitoring inter- } \\
\text { firm collaboration } \\
\text { and understanding } \\
\text { its role (substitute } \\
\text { or complement) } \\
\text { with respect to the } \\
\text { activity of coaches } \\
\text { and mentors }\end{array}$ \\
\hline
\end{tabular}


Table 1.1 (continued)

\begin{tabular}{|c|c|c|c|}
\hline $\begin{array}{l}\text { Economic } \\
\text { role }\end{array}$ & Economic drivers & $\begin{array}{l}\text { Main actors and } \\
\text { key success factors }\end{array}$ & Strategic implications \\
\hline $\begin{array}{l}\text { Bridging } \\
\text { institution }\end{array}$ & $\begin{array}{l}\text { Economies of } \\
\text { scale and scope } \\
\text { Learning } \\
\text { economies }\end{array}$ & $\begin{array}{l}\text { Quality, size } \\
\text { and variety } \\
\text { of academic } \\
\text { competencies } \\
\text { at the affiliated } \\
\text { university } \\
\text { Clarity in the } \\
\text { regulations } \\
\text { governing } \\
\text { academic } \\
\text { entrepreneurship } \\
\text { Coaches and } \\
\text { mentors (ability } \\
\text { to operate both } \\
\text { according to } \\
\text { technology- } \\
\text { push and } \\
\text { demand-pull) }\end{array}$ & $\begin{array}{l}\text { Deciding the effort to } \\
\text { be spent on } \\
\text { technology-push } \\
\text { and demand-pull } \\
\text { activities } \\
\text { Building the network } \\
\text { with academic labs } \\
\text { and departments }\end{array}$ \\
\hline
\end{tabular}

that - again - must only be considered as a stimulus for debate and as possible directions for further research.

\subsubsection{Ownership and Governance}

Just like any other economic entity, the profile and the strategic direction taken by a university incubator will be heavily dependent on its ownership structure. An incubation program run by an administrative office of a university, a non-profit consortium such as I3P, and a for-profit incubator jointly owned by a university and an investment fund, will be subject to different charters and missions, will follow different strategies and - of course - will achieve different results. As a consequence, the connection between ownership structure and the performance of an incubation program should not be overlooked, and must be taken into account both when defining the former and when assessing the latter.

Closely connected to the issue of ownership is that of governance. As shown in the previous subsection, incubators operate a complex business model that is not easy to frame in terms of modes of value creation, assessment of the costs incurred, evaluation of the direct impact and the 
externalities generated. Moreover, incubators often operate at the intersection between for-profit and non-profit sectors. Therefore, the governance of an incubator must define clear objectives and metrics for evaluating the program, taking into account the long time constants over which many of these indicators will develop. The revenue model of an incubator must also be coherent with the expected outcomes, so that its operations can run in a clear and unambiguous way. In the case of I3P, having revenues linked to start-up creation has indeed led to a clear and strong incentive to generate a strong flow of potential start-ups and a significant number of new ventures. However - as discussed - this may not have generated a sufficiently strong incentive mechanism to work on the growth of these companies, which is something that could be corrected by creating a parallel and forprofit acceleration program.

Finally, and especially for incubators that are supported by public funds, a constant monitoring of the market conditions must be carried out. Specifically, it is appropriate to check whether a market failure justifying public intervention is still present or whether - perhaps as a result of the work carried out by the same incubator - the start-up ecosystem has become sufficiently mature to operate independently. Failing to do so opens the risk of crowding out private players who might offer the same supporting role to start-ups (Thierstein and Willhelm, 2001).

\subsubsection{Vertical and Horizontal Integration Choices}

The dual nature of the incubator as a consultancy company and a two-sided market also involves making key strategic choices with respect to vertical integration. For example, legal advice to start-ups can be provided by an in-house lawyer or by a partner law firm. In the former case, there will be a tighter control over the resource (provided incubator managers are able to hire and manage legal experts) and a higher fixed cost. In the latter case, the incubator will have lower costs, less control over the resource, but may partner with multiple service providers, thus enriching the choice available to start-ups and lowering the risk associated with nonperformance by the resource.

Furthermore, a higher degree of vertical integration (i.e. in-house experts) will tend to concentrate valuable and specific expertise within the incubator. Conversely, a lower degree of vertical integration (i.e. partnering with outside experts) will spill these competencies into the local startup ecosystem (i.e. the partner lawyer will learn how to deal with start-ups beyond those that operate in the incubation program). Therefore, vertical integration choices will be made based on costs and competencies, but may 
also take into account the degree of strategic control the incubator wants to have over key resources in the local start-up ecosystem.

This aspect is particularly critical when dealing with the core consultancy that is provided by incubators, namely start-up strategy. At its heart, this is about choosing the right mix of coaches and mentors. As mentioned in the earlier footnote, the former are usually employed and paid by the incubator, while the latter are independent partners who work pro bono or are paid directly by the start-ups (usually with success fees). When starting an incubation program in a strong start-up ecosystem, it is likely that good mentors will abound, and coaches may not be needed at all. However, when an incubator starts operating in a weaker ecosystem, mentors might not exist (and aspiring ones might not be credible enough), thus making it mandatory to train and develop a team of coaches. As time goes by - and as the ecosystem evolves - it is likely that the optimal mix between coaches and mentors will change. However, it might not be easy to manage this shift, due to organizational inertia and the fear coaches may have of losing their jobs. The choice made by I3P to rely heavily on coaches while contracting them as freelancers could be seen as a way to keep the middle path in this strategic choice.

Horizontal integration is choosing to specialize by industry or by phase of the start-up development lifecycle. As already mentioned, the right balance must be found between the benefits accruing from economies of scale and learning both across the board and within each possible specialization.

\subsubsection{Organizational Aspects}

Regardless of the strategic choices made, it should be recognized that an incubator is a firm, albeit a peculiar one. Viewing it as a development agency or an academic institution would probably undermine the credibility and capability of the incubator's staff to support start-ups effectively. In order to support entrepreneurs, one must share the same culture and be subject to similar dynamics. This is of course difficult if one operates within an entity with a different culture, processes and set of incentives.

That said, and based on the four economic roles discussed above, a number of operational decisions must be made. The most important decisions are probably associated with the management of the incubator's human resources, including recruitment, incentive schemes, professional development and organization. After all, an incubator is a 'people business', and the quality of its human resources and the way they are organized will determine its capability to perform effectively.

The importance of creating and sustaining external relations at senior 
Table 1.2 Required capabilities for incubator coaches

\begin{tabular}{|c|c|}
\hline Role & Typical competencies and skills \\
\hline Consultancy & $\begin{array}{l}\text { - Analytical skills, for understanding markets and industries } \\
\text { - Competencies in innovation management, for framing and } \\
\text { proposing strategy } \\
\text { - Competencies in finance, for interfacing with investors and } \\
\text { banks } \\
\text { - General competencies in administrative, financial, legal and IP } \\
\text { affairs (gatekeeping with professional services providers) } \\
\text { - Communication skills, both concerning their personal } \\
\text { capability to present and for tutoring entrepreneurs } \\
\text { - People management skills, for coordinating the work of } \\
\text { junior consultants and analysts } \\
\text { - People management skills, for coaching entrepreneurs } \\
\text { (understanding their personal shortcomings and defining ways } \\
\text { to overcome them) }\end{array}$ \\
\hline $\begin{array}{l}\text { Network } \\
\text { creation }\end{array}$ & $\begin{array}{l}\text { - Personal credibility and strong understanding of business } \\
\text { dynamics, in order to create links with existing firms } \\
\text { - Personal credibility and strong understanding of the } \\
\text { technological state-of-the-art, in order to create links with } \\
\text { academic staff }\end{array}$ \\
\hline Deal-making & $\begin{array}{l}\text { - Capability to screen people and avoid engaging in impossible } \\
\text { deal-making processes } \\
\text { - Analytical skills for supporting negotiations } \\
\text { - Communication and personal skills for supporting negotiations }\end{array}$ \\
\hline
\end{tabular}

level is a strong requirement especially of the program's top management (CEO and/or managing director). At the same time, coaches (and mentors) must possess a significant variety of skills and competencies given the manifold nature of their work, as summarized in Table 1.2.

The skill set required for coaches is very broad and not easily found on the market. This suggests that an incubator should train these key personnel 'in-house' rather than attempt their external recruitment. Recruiting from other incubators is of course possible, but carries the risk that experience gained in a different start-up ecosystem might not be applicable in the new location. Another possibility is looking for people with a similar skill set, for instance in the management consultancy industry. However, caution is advised because there is a big difference between working with start-ups and established companies.

Finally, the competencies and skills listed above apply with different weights and nuances along the lifecycle of a start-up. An incubator might 
therefore decide to split the incubation process into phases and have different and specialized start-up coaches looking after each phase. The trade-off here is between the benefits of specialization or the value of having a single, well-recognized coach (who entrepreneurs get to know and trust) taking the start-up all the way through the process from beginning to end.

\subsection{CONCLUSIONS}

This chapter has attempted to discuss the nature of academic incubation based on the experience of a single and well-established program, i.e. the I3P incubator of Politecnico di Torino. Based on this experience, the author has attempted to build an economic analysis of what constitutes an academic incubation program by highlighting four roles, i.e. that of a consultancy company, a two-sided market, an industry cluster and a bridging institution. This analysis constitutes a basic theoretical and unvalidated discussion. However, this could lead to further empirical research, in order to gain a deeper understanding of the economic foundations of academic incubation.

Then, in order to provide some preliminary practical advice, this analysis has been used to highlight three main areas where incubator managers must take key decisions: ownership and governance, vertical and horizontal integration, and organizational policies.

\section{NOTE}

1. Here, and for the remainder of the chapter, we will use the term coach to describe incubator personnel acting as consultants to start-ups. In the incubation industry, this role may also be referred to as tutor, consultant or expert. Coaches are different from mentors, the latter being independent experts with an entrepreneurial or managerial background, who share their experience and their networks with start-ups either pro bono or via a contractual link with the start-ups. However, the incubator does not usually pay mentors.

\section{REFERENCES}

Cantamessa, M. (2015), 'Verso la Entrepreneurial University del XXI Secolo', Opening lecture of the 2015-2016 Academic Year, Politecnico di Torino (in Italian).

Chesbrough, H.W. (2006), Open innovation: The new imperative for creating and profiting from technology (Boston, MA: Harvard Business School Publishing).

Erkko, A. and H. Yli-Renko (1998), 'New, technology-based firms as agents of technological rejuvenation', Entrepreneurship and Regional Development, 10, 1. 
Etzkowitz, H. and L. Leydesdorff (2000), 'The dynamics of innovation: from National Systems and "Mode 2" to a Triple Helix of university-industrygovernment relations', Research Policy, 29 (2), 109-23.

Feld, B. (2011), Startup communities: Building an entrepreneurial ecosystem in your city (Hoboken, New Jersey: Wiley).

Hekkert, M.P., R.A.A. Suurs, S.O. Negro and S. Kuhlmann (2007), 'Functions of innovation systems: A new approach for analysing technological change', Technological Forecasting and Social Change, 74, 4.

Hoppe, H.C. and E. Ozdenoren (2005), 'Intermediation in innovation', International Journal of Industrial Organization, 23 (5), 483-503.

Kremic, T. (2003), 'Technology transfer: a contextual approach', The Journal of Technology Transfer, 28 (2), 149-58.

Moretti, E. (2012), The new geography of jobs (New York: Houghton Mifflin Harcourt).

OECD-EC (2012), 'A guiding framework for entrepreneurial universities', http:// www.oecd.org/site/cfecpr/EC-OECD $\% 20$ Entrepreneurial $\% 20$ Universities $\% 20$ Framework.pdf (accessed 30 April 2016).

Peters, L., M. Rice and M. Sundararajan (2004), 'The role of incubators in the entrepreneurial process', The Journal of Technology Transfer, 29, 1.

Porter, M.E. (1996), 'Competitive advantage, agglomeration economies, and regional policy', International Regional Science Review, 19 (1-2), 85-90.

Ries, E. (2011), The lean startup: How today's entrepreneurs use continuous innovation to create radically successful businesses (New York: Random House).

Rochet, J.C. and J. Tirole (2006), 'Two-sided markets: A progress report', The RAND Journal of Economics, 37 (3), 645-67.

Simon, M., S.M. Houghton and K. Aquino (2000), 'Cognitive biases, risk perception, and venture formation: How individuals decide to start companies', Journal of Business Venturing, 15 (2), 113-34.

Thierstein, A. and B. Willhelm (2001), 'Incubator, technology, and innovation centres in Switzerland: features and policy implications', Entrepreneurship \& Regional Development, 13 (4), 315-31.

Zomer, A. and P. Benneworth (2011), 'The rise of the university's third mission', in J. Enders, H.F. de Boer and D.F. Westerheijden (eds), Reform of Higher Education in Europe (Rotterdam: Sense Publishers). 